\title{
Disease and pest management in apple: Farmers' perception and adoption in J\&K state
}

\author{
M. A. Beigh ${ }^{1}$, Quadri Javeed Ahmad Peer ${ }^{2 *}$, S. K. Kher ${ }^{3}$ and N. A. Ganai ${ }^{4}$ \\ ${ }^{1}$ Division of Extension Education \& Communication, Sher-e-Kashmir University of Agricultural Science \& Technology \\ Kashmir (J\&K), INDIA \\ ${ }^{2}$ Department of Agriculture Statistics, Economics and Extension, FOA, Wadura, Sher-e-Kashmir University of \\ Agricultural Science \& Technology Kashmir (J\&K), INDIA \\ ${ }^{3}$ Division of Extension Education, Sher-e-Kashmir University of Agricultural Science \& Technology Jammu \\ (J\&K), INDIA \\ ${ }^{4}$ Krishi Vigyan Kendra Kupwara, Sher-e-Kashmir University of Agricultural Science \& Technology, Kashmir \\ (J\&K), INDIA
}

*Corresponding author. E.mail: qadrijavid2008@gmail.com

Received: November 8, 2014; Revised received: January 29, 2015; Accepted: April 18, 2015

\begin{abstract}
Diseases and pests are one of the limiting factors for low productivity of the fruit crops in Kashmir valley, India. A study on management of resources with respect to disease and pest management of apple and extent of adoption of recommended plant protection technology was undertaken for increasing apple production in Kashmir valley of $\mathrm{J}$ and $\mathrm{K}$ State. District Baramulla was selected purposively on the basis of maximum area and production under apple crop. A sample size of 200 apple growers 50 each from 4 villages were selected randomly. The study revealed that the perception index regarding attributes of technology recommended in two diseases viz. San Jose Scale and Apple Scab was $68.88 \%$ and $80.76 \%$ in respect of profitability $(83.97 \%)$, simplicity-complexity each $63.57 \%$ and $54.27 \%$ for practicability attributes of technology. The data further showed that the farmers adoption level under Chemical control was high at silver tip to green tip stage (80\%) and fruit let pea size stage $(78 \%)$ and medium adoption was observed at pink bloom (bud) stage (74\%), petal fall stage (74\%) walnut size apple stage $(70 \%)$ on Apple Scab similarly, the extent of adoption was low (45\%) for mechanical and no chemical control measures under clean cultivation. In case of San Jose Scale the farmers adoption level regarding name of chemical, its dose, quantity of water required per acre for preparing spray solution and time of spray at late dormant spray, (feb, March) was high (80\%). The findings will help to improve the level of farmers' knowledge to increase apple production in Kashmir valley.
\end{abstract}

Keywords: Apple, Adoption, Disease, pest management and Plant protection

\section{INTRODUCTION}

India is the second largest producer of fruits after China, with a production of 44.04 million tonnes from an area of 3.72 million hectares (FAO, 2010) A large variety of fruits are grown in diverse agro-climatic zones in India. The fruit production was 748.78 lakh tons during 2010-11 and in 2011-12 it was 775.25 lakh tones (National Horticulture Board 2013-2014). Apple (Malus domestica) belongs to family Rosacea and is grown in temperate and subtropical regions of the country. It is known for its fair quality, characteristic flavour and is widely grown in Kashmir valley. Presently the area under apple cultivation in Jammu and Kashmir is 1.57 lakh hectares having annual production of 13.48 lakh metric tonnes (Anonymous, 2013). Among the temperate fruits in $\mathrm{J} \& \mathrm{~K}$, apple is the principle crop accounting for more than 43 per cent of area, whereas in terms of fruit production, its share is more than 78 per cent. The percentage share of this fruit in respect of area and production at national level is 2.4 and 2.0 per cent respectively. The Jammu \& Kashmir state has created a niche in quality apple production and has made tremendous progress during the last decade as the area in the state has increased 16 times, production by about 60 times and productivity by 5 fold. The variation in the physical characteristics of fruits such as size of fruit, seed content, colour, average weight and diameter are quantitatively inherited characters and are also directly affected by environment such as soil, rainfall, size of the crop, fertilization etc., (Shabeena et al., 2008) found that the combination of these traits are an important factor contributing to fruit quality. The biochemical characteristics such as, sugar content, total acidity and sugar/acid ratio were cultivar-specific (Suszyna, 2004). Most of the cultivars are very old and have strong tendency to alternate bearing.

In Jammu and Kashmir production constraints of Apple in the state, among others include a complex of key and secondary insects, pests and diseases. Under 
Kashmir conditions, the most important pests attacking Apple are European Red Mite (Pannonychusulmi), Two spotted mite (Tetranychusurtica), Sanjose scale (Quadraspidiotus perniciosus) etc. Not only pests but also many diseases cause huge economic loss. Major diseases attacking Apple are Scab (Venturia inaequalis), Brown rot (Sclerotinia fructigina), Sootybloch (Gloedes pomigena) etc. Fungicides such as Carbendazim, Mancozeb, Myclobutamil and Fenarimol etc have been recommended against scab (Anonymous, 2014). Similarly Dimethoate, Phosphamidon, Ethion, Endosulphon, Malation and Carbaryl etc have been recommended on Apples against key arthropod pests (Anonymous, 2014).

The pests and diseases of the apple trees not only reduce the productive capacity of trees but also affect adversely the fruit quality. Proper disease and pest management beyond doubt, contribute significantly in increasing the crop production on sustainable basis. Insects, pests and diseases frequently causing havoc to crops are quoted by (Sharma, 2000) to be one of the major shortcomings of horticulture. There are wide number of pests and diseases which are widely reported and quoted in a number of sources.

Apple contributes 83 per cent of the total fruit production of $\mathrm{J} \& \mathrm{~K}$ state. The annual turnover from the sale proceeds of apple are estimated around Rs. 300 crore. The productivity of apple in $\mathrm{J} \& \mathrm{~K}$ is around 12 tonnes per hectare, far below the level achieved by other countries (40-60 tonnes/ha).

The soundness, suitability and feasibility of the recommended technology for control of pests and diseases has a direct bearing on extent of adoption at the farmers' fields. With this objective in mind, a study was undertaken in J\&K state to ascertain the farmers' perception about the recommended plant protection technology and its level of adoption, pertaining to apple cultivation.

\section{MATERIALS AND METHODS}

The study was conducted in Kashmir Valley of $\mathbf{J}$ and K State. District Baramulla was selected purposively on the basis of maximum area and production under apple crop. Two villages from teshil Sopore namely Bomei and Logripora were selected purposively on the basis of maximum irrigated area under apple cultivation and Two villages from teshil Patten namely Chechilora and Warpora were selected purposively having maximum rainfed area under apple cultivation . After the selection of villages, from each village, 50 respondents were selected randomly, making a total sample size of 200 apple growers .The interview schedule was pre-tested in a non-sampled area and then making necessary modifications after the data were collected in person from the farmers. Among the various pests and diseases, the study was confined to Apple Scab and San Jose Scale, being the major disease and pest of apple respectively. The farm- ers' perception was measured on three -attributes of the technology viz., profitability, simplicity -complexity and practicability and the extent of adoption was expressed as high, medium and low as described by the method given by (Choudhary, 1995). For managing sanjose Scale two methods were adopted which include biological and chemical method, however in case of apple scab, only chemical control was adopted. The data were collected with the help of well-structured interview schedule, statistically analyzed in terms of frequency counts, percentages and weighted mean scores.

\section{RESULTS AND DISCUSSION}

Farmers perception on various attributes of technology recommended for control San Jose Scale and Apple Scab: It is evident from the figures presented in Table 1 that the farmer's perception on various attributes of technology was medium for profitability and practicability but high for simplicity- complexity for control of San Jose Scale. From the findings it was observed that 68.88 per cent farmers perceived the technology profitable, 83.97 per cent simple and 54.27 per cent as practicable respectively. The data further showed that the perception index was 80.76 per cent, 83.97 per cent and 63.57 per cent in respect of profitability, simplicity-complexity and practicability attributes of technology recommended for control of Apple Scab which showed a high level of perception for profitability and simplicity-complexity but medium for practicability attributes. Thus, it can be inferred that perception of farmers on the whole was satisfactory.

The medium level of profitability and practicability in case of San Jose Scale and medium level of practicability in Apple Scab may be due to the farmers opinion about the recommended dose of chemicals per 100 litres of water, being insufficient to control the pests and diseases. In Apple Scab, most of the farmers were unaware about the recommended chemicals used at different crop stages. The findings are in line with the findings of (Williamson et al., 2003) who had observed that the way farmers perceive the benefits and costs of different pest management strategies will have an impact on their pest management decisions, (Reddy, 1989) reported that majority of the contact farmers fall under medium category in respect of perception on various attributes of technology. (Verma, 1985) reported that in case of rapeseed mustard farmers perceived medium level of profitability, simplicity and practicability about the control of sawfly and medium level of simplicity and practicability put high profitability about the painted bug and mustard aphid. About spraying at economic threshold stage to control mustard aphids, the farmer's perception on profitability, simplicity and practicability was low.

Extent of adoption on control of San Jose Scale: It is clear from the Table 2 that the recommendations for control of San Jose Scale are grouped into two components 
Table 1. Farmers perception on various attributes of technology recommended for control San Jose Scale and Apple Scab $(n=200)$.

\begin{tabular}{llccc}
\hline S. N. & Attributes of Technology & Mean Perception Score & Perception Index (\%) & Level \\
\hline \multicolumn{2}{l}{ San Jose Scale } & & & \\
\hline 1 & Profitability & 23.28 & 68.88 & Medium \\
2 & Simplicity-complexity & 28.13 & 83.97 & High \\
3 & Practicability & 18.60 & 54.27 & Medium \\
\hline \multicolumn{2}{l}{ Apple Scab } & & & High \\
\hline 1 & Profitability & 46.84 & 80.76 & High \\
2 & Simplicity-complexity & 48.70 & 83.97 & Medium \\
3 & Practicability & 36.87 & 63.57 & \\
\hline
\end{tabular}

Table 2. Extent of adoption on control of San Jose Scale ( $n=200)$.

\begin{tabular}{llcc}
\hline S. N. & Plant protection components & $\begin{array}{c}\text { Weighted mean } \\
\text { adoption scores }\end{array}$ & Level \\
\hline San Jose Scale & 0.00 \\
\hline 1. & Biological control & & High \\
2 & Chemical control & 0.00 & Medium \\
a & Dormant spray & 0.80 & Low \\
b & Late dormant spray & 0.64 & 0.32 \\
c & Petal fall spray & 0.00 & \\
d & d. Fruit development spray (Walnut size stage) & & \\
\hline
\end{tabular}

Table 3. Extent of adoption on control of Apple Scab $(n=200)$.

\begin{tabular}{llcc}
\hline S. N. & Plant protection components & Weighted mean adoption scores & Level \\
\hline l & Chemical control (7-spray schedule) & 0.80 & High \\
a & Silver tip to green tip stage & 0.74 & Medium \\
b & Pink bloom (bud) stage & 0.74 & Medium \\
c & Petal fall stage & 0.78 & High \\
d & Fruit let-pea size stage & 10.70 & Medium \\
e & Fruit development stage(walnut size) & 0.43 & Low \\
f & Fruit development stage (fruits half size) & 0.36 & Low \\
g & Pre-harvesting stage & 0.38 & Low \\
h & Use of stickers & & Low \\
2 & Clean cultivation & 0.45 & 0.00 \\
a & i. Mechanical control measures & & \\
b & ii. Chemical spray & & \\
\hline
\end{tabular}

viz. Biological and Chemical measures. The findings have been presented component wise in terms of weighted mean scores. The results revealed that farmers adoption level regarding name of chemical, its dose, quantity of water required per acre for preparing spray solution and time of spray at late dormant spray, (feb, March) was high (80\%). The extent of adoption was medium (64\%) at petal fall stage. For the spray during fruit development spray (walnut size), the level of adoption was low (32\%). These findings are agreement with the findings of (John 1994) who had reported that the extent of adoption of mandarin growers for insect pest and disease control was medium level $(62 \%)$ of mandarin cultivation. The 
study further inferred that none of the farmers had adopted recommendations for dormant spray (Dec -Feb), pre-harvesting spray and at biological control measures.

The reasons for non-adoption of missed sprays can be attributed to the severe cold, frost and snow fall during the recommended time period. For the development of the fruit. The spray is done when the fruits are of walnut size, farmers did not consider the spray important and they were of the opinion that if late dormant spray is managed effectively, the damage caused by San Jose Scale could be reduced considerably. Further, the farmers were not aware about the recommendations on pre-harvest spray or biological control.

Extent of adoption on control of Apple Scab: Data showed in Table 3 that the farmers' adoption level under Chemical control was high at silver tip to green tip stage (80\%) and fruit let pea size stage (78\%). A medium adoption was observed at pink bloom (bud) stage $(74 \%)$, petal fall stage $(74 \%)$ walnut size apple stage $(70 \%)$ respectively. However, the adoption level was low in case of fruit development stage, when fruits are of half size (43\%) and pre harvesting stage (36\%). Regarding use of stickers also the adoption level was low $(38 \%)$. Similarly, the extent of adoption was low $(45 \%)$ for mechanical and no chemical control measures under clean cultivation.

The medium level of adoption at various stages was due to the fact that the apple growers did not find the recommended chemicals effective in the control of Apple Scab, although they were aware about such chemicals. There were also other recommended fungicides but farmers were not aware about them. Similarly, the respondents were not convinced about the recommended dose of the chemicals due to their ineffectiveness. The low adoption of recommended spray schedule at fruit development stage and pre-harvesting stage may be due to the respondents' opinion, that sunny days, clear weather and high temperature did not increase the incidence of Apple Scab and thus there was no need of wide scale control measures. A similar adoption level in the use of sticker was attributable to the respondents' opinion in light of the above observations. These findings are in conformity with the findings of (Yavlkar et al., 1991) who had reported that half of the respondents accepted plant protection measures to medium extent in orange cultivation, while more than one-forth respondents had low level of adoption. Only 24\% respondents used recommended plant protection measures to the highest extent. The results were also supported by (Kude et al., 1991) who observed that majority of the respondents were not using plant protection measures, 6\% respondents adopted 3 sprays, 10\% applied 4 sprays and $7 \%$ used 5 sprays but only 2-3\% farmers adopted 6 sprays for cotton crop. These findings are in agreement with that of (Thakur, 2008) who had reported that generally, 9-10 sprays are required to control the disease. Apple scab in India can be managed very well with modern fungicides. Apple growers in kashmir valley have adopted the prescribed schedule of chemical sprays to control the disease. The chemical sprays have reduced the loss due to apple scab in India to a considerable extent. The use of fungicides in India to control apple scab is playing a significant role to improve productivity, sustain production and assure quality of harvest.

A communication gap was the most important reason for low adoption of mechanical control measures. As regards the use of chemical spray under clean cultivation, it was observed that respondents were absolutely unaware about such recommendations.

\section{Conclusion}

It was concluded that the farmers perception on various attributes of technology was of medium level for profitability and practicability attributes but high for simplicity- complexity attribute for control of San Jose Scale and general level of perception was high for profitability and simplicity-complexity and practicability attribute of technology recommended for control of Apple Scab Thus, it can be inferred that perception of farmers on the whole was satisfactory. The study further concluded that none of the apple growers had adopted biological measures for control of San Jose Scale. Similarly, none of the respondents had adopted dormant spray and pre-harvesting spray under chemical control measures. With regard to farmers' adoption on control of Apple Scab, none of the apple growers had adopted recommendations regarding sprays of chemical under clean cultivation. Majority of the orchardists were unaware of the spray Schedule and sprayed no fungicides and pesticides at recommended stages (green tip stage, fruit let pea size stage, pink bloom (bud), petal fall stage and walnut size apple stage). The study would help to improve the level of farmers' knowledge to increase apple production in Kashmir valley.

\section{REFERENCES}

Anonymous (2014). Annual Progress Report. Department of Horticulture J\&K Government, Srinagar,pp.1- 2

Anonymous (2013).Packages of practices. Directorate of Skuast-k Shalimar, Srinagar pp. 23-2

Choudhary, B.N. (1995) Technology assessment and refinement through IVLP: Operational guideline. ICAR, New Delhi, India

FAO,(2010) Production year Book. Food and Agricultural organisation, Rome, Italy 55: 178.

John, V. (1994). Knowledge gape and adoption recommended farm practices for Mandarine cultivation in Mizoram. M.Sc. thesis (Unplished), CCS Haryana Agricultural University, Hissar.

Kude, N.R., Saugne M.A and Ingle P. (1991). Adoption of recommended technologies under dryland farming. Maharashtra Journal. Extension. Education. 10(2): 
227- 233

NHB, (2013-14). Horticulture production data base of the National Horticultural Board, Gurgaon.

Reddy, M.M. (1989). A study on role expectation and role performance of contact farmers as perceived by Eos, contact farmers and other farmers (Unpublished) M.Sc. thesis, Andhra Pradesh Agril. University.

Shabeena, M., Banday, F.A., Majid, B.A., Nazir, N. (2008). Physio-chemical characteristics of various improved cultivars of apple under high density plantation on M9 root stock. Environment and Ecology 26(4A): 1739-1741.

Sharma, R.C. (2000). Need for Research for improving the quality of fruits and vegetables for processing industry. In V.K Sharma \&K.C. Azad (Eds.), Horticulture Technology. Vision 2000 \& Beyond (2000 ed.,vo.2.p11). New Delhi :Deep and Deep Publications Pvt. L.

Suszyna, J. (2004). The variability of the acidity and the extract in apple fruit from trees cultivated in the Sandomierz region. Folia Universitatis Agriculturae
Stetinensis Agricultura 96: 189-192.

Sheoran, O.P. ( 2006). Statistical Package for Agricultural Workers. Choudhary Charan Singh Haryana Agricultural University, Hissar.

Thakur, V.S. (2008). Apple diseases chemical control in India. Acta Hort. 769. 177-184

Verma, H.K. (1985). Production promotion process and problem of Rapseed-Mustard in Haryana.Ph.D. thesis (Unplished), Department of Extension Education, HAU, Hisar.

Williamson SL, ittle A, Ali MA, KIman M, Meir C, Oruko L. (2003). Aspects of cotton and vegetable farmers' pest management decision-making in India and Kenya. Int. J. Pest Man.49:187-198.

Yavalkar,P.B., Nikhade, D.M. and Bhopal, R.S. (1991). Correlation of adoption of plant protection recommendations of Kolsi by Orange growers- A Path Analysis", Maharashtra Journal of Extn. Edu. 10(2):216-221. 